\title{
Carbetocin versus Oxytocin for the Prevention of Postpartum Hemorrhage in Cesarean Deliveries: A Retrospective Study of Two Consecutive Periods
}

\author{
Pierre Delorme, MD, Msc $c^{1,2,3}$ Gilles Kayem, MD, $\mathrm{PhD}^{1,2,3,4}$ Hélène Legardeur, $\mathrm{MD}^{4,6}$ \\ Louise Anne Roux-Dessarps, MD ${ }^{4,5}$ Guillaume Girard, MD ${ }^{1,4}$ Geraldine Meunier, MSc ${ }^{4}$ \\ Hawa Keita, MD, $\mathrm{PhD}^{7,8,9}$ Laurent Mandelbrot, MD, $\mathrm{PhD}^{4,9}$
}

\footnotetext{
${ }^{1}$ Department of Obstetrics and Gynecology, Trousseau Hospital, FHU Prema, Paris, France

2 Obstetrical, Perinatal and Pediatric Epidemiology Research Team (Epopé), Center for Epidemiology and Statistics Sorbonne Paris Cité, Paris Descartes University, Paris, France

3 Paris Sorbonne University, Paris, France

${ }^{4}$ Department of Obstetrics and Gynecology, Louis Mourier Hospital, FHU Prema, Paris, France

${ }^{5}$ Department of Obstetrics and Gynecology, Centre Hospitalier Simone-Veil, Eaubonne, France

6 Department of Obstetrics and Gynecology, Centre Hospitalier Universitaire Vaudois, Université de Lausanne, Lausanne, Switzerland

7 Department of Obstetric Anesthesia-Intensive Care, Louis Mourier Hospital, Paris, France

${ }^{8}$ Department of Pediatric and Obstetric Anesthesia-Intensive Care, Necker Enfants Malades Hospital, APHP, Paris, France

9 Paris University, Paris, France
}

Address for correspondence Gilles Kayem, MD, PhD, Department of Obstetrics and Gynecology, Trousseau Hospital, APHP, Paris, France (e-mail: gkayem@gmail.com).

Am J Perinatol Rep 2020;10:e241-e246.

\begin{abstract}
Keywords

- oxytocin

- carbetocin

- postpartum hemorrhage

- cesarean delivery

Objective The aim of the study is to investigate whether carbetocin prevents postpartum hemorrhage (PPH) more effectively than oxytocin

Methods This historical retrospective single-center cohort study compares women who underwent cesarean deliveries during two periods. During period A, oxytocin was used as a 10-unit bolus immediately after delivery, with 20 units thereafter infused for 24 hours. During period B, carbetocin in a single $100-\mu \mathrm{g}$ injection replaced this protocol. The main outcome was PPH, defined as a decline in hemoglobin of more than $2 \mathrm{~g} / \mathrm{dL}$ after the cesarean. The analysis was performed on the overall population and then stratified by the timing of the cesareans (before or during labor). A logistic regression analysis was performed.

Results This study included 1,796 women, $52 \%$ of whom had a cesarean before labor; $15 \%$ had a PPH. The crude PPH rate was lower in period B than in period A ( 13 vs. $17 \%$, respectively, odds ratio $0.75,95 \%$ confidence interval $[\mathrm{Cl}]: 0.58-0.98)$. The difference was no longer significant in the multivariate analysis (adjusted odds ratio: $0.81,95 \% \mathrm{Cl}$ $0.61-1.06$ ). Results were similar when stratified by the timing of the cesareans (before or during labor).

Conclusion Carbetocin is not superior to oxytocin in preventing PPH. However, it does provide the advantage of requiring a single injection.
\end{abstract}

received

January 24, 2020

accepted

April 9, 2020
DOI https://doi.org/

10.1055/s-0040-1715163. ISSN 2157-6998.
Copyright $\odot 2020$ by Thieme Medical Publishers, Inc., 333 Seventh Avenue, New York, NY 10001, USA. Tel: +1(212) 760-0888.
License terms

(c) (i) $\ominus$ (\$) 
Postpartum hemorrhage (PPH) accounts for 125,000 deaths per year worldwide and is the leading cause of maternal death. ${ }^{1}$ Despite significant progress, it accounts for $18 \%$ of maternal deaths and $80 \%$ of preventable causes in France. ${ }^{2}$ Uterine atony is its principal cause, responsible for nearly $70 \%$ of the cases. ${ }^{3}$ Active management of delivery with uterotonic agents is thus recommended by all national guidelines and is reported to halve the PPH rate. ${ }^{4}$ According to a 2013 Cochrane review, prophylactic oxytocin can prevent PPH, and an intravenous (IV) bolus dose of 10 IU is recommended as part of active management of the third stage of labor. ${ }^{5}$ The World Health Organization recommendations for PPH treatment and prevention also advise the use of 10 units of oxytocin (intramuscularly or intravenously) for the prevention of PPH in all births. ${ }^{6,7}$ This injection is often followed by a maintenance dose of 10 IU over several hours because the half-life of oxytocin is 4 to 10 minutes. Carbetocin, a synthetic oxytocin analog with a half-life of 40 minutes, has been available for 20 years and is hoped to provide better efficacy and a greater ease of use.

The main indication for which carbetocin has been proposed is cesarean delivery, because this mode of delivery is associated with a higher prevalence of severe $\mathrm{PPH}$ and requires invasive second-line therapies three times more often than vaginal deliveries do. ${ }^{8}$ It has been evaluated in women with cesareans in small randomized trials and by subjective or post hoc judgment criteria (use of other uterotonics or fundal height in the immediate postpartum period). A 2018 Cochrane meta-analysis concluded that prophylactic carbetocin does not result in a lower incidence of $\mathrm{PPH}$ $>500 \mathrm{~mL}$ in cesarean deliveries, with a risk ratio of 0.71 (0.47-1.07). ${ }^{9}$ This result was nonetheless limited by the number of studies available for this outcome (only six trials and 678 women with cesareans) and the moderate quality of the studies. On the other hand, blood loss and the need for additional uterotonic agents fell significantly, and other recent meta-analyses appear to show that carbetocin is superior to oxytocin. ${ }^{10,11}$

In 2012, our tertiary referral center replaced oxytocin by carbetocin for use in preventing PPH in cases of cesareans before or during labor. The objective of this study was to investigate whether the use of a single injection of carbetocin was more effective than an oxytocin bolus and 24-hour infusion for preventing PPH in a large sample of women with a cesarean delivery before or during labor.

\section{Materials and Methods}

This is a historical retrospective cohort study of patients who underwent cesarean deliveries in a single tertiary referral center in Paris region, France. Two periods were compared according to whether PPH prophylaxis used oxytocin (period A from January 1, 2011 to December 31, 2012) or carbetocin (period B from May 1, 2013 to December 31, 2014).

$\mathrm{PPH}$ prevention is used according to a strict protocol in our obstetrics department, in accordance with international recommendations. The administration protocol during period A was 10 IU by IV infusion for 1 minute then 20 IU as an IV drip infusion for 24 hours; during period B, it called for carbetocin, $100 \mu \mathrm{g}$, as a single IV injection.

This study included all women with a cesarean delivery before or during labor after 24-weeks of gestation (WG) during both periods. The Ethics Committee with jurisdiction over our institution has provided a written approval statement confirming that our study complies with all international and French ethical rules and laws.

Our purpose was to study the prevention of PPH due to atony. Therefore, we excluded pregnancies with significant risk factors for other causes of PPH, including placenta previa, coagulation disorders, thrombocytopenia $<150,000$ platelets/ $\mathrm{mm}^{3}$, uterine artery lesions, myoma previa, placental abruption, or uterine rupture. Women who had a transfusion for severe anemia without PPH were also excluded.

Quantification of blood loss in cases of cesarean deliveries is always difficult, due to the incomplete collection of losses, the mixing of amniotic fluid with maternal blood, etc. To identify women who had PPH after a cesarean delivery, we recorded for each of her last hemoglobin $(\mathrm{Hb})$ concentration measured before this delivery (always performed during the preceding month) and the $\mathrm{Hb}$ concentration between postoperative day 1 and 3 . PPH was then defined as a decline in the $\mathrm{Hb}$ concentration of more than $2 \mathrm{~g} / \mathrm{dL}$, and severe PPH by a reduction in $\mathrm{Hb}>4 \mathrm{~g} / \mathrm{dL}^{12}$

To take intraoperative transfusions into account, we estimated that a packed red blood cell unit increased the $\mathrm{Hb}$ concentration by $0.5 \mathrm{~g} / \mathrm{dL}$. One unit of packed red cells is expected to increase the $\mathrm{Hb}$ concentration by $1 \mathrm{~g} / \mathrm{dL}$ in a patient of average height and weight. ${ }^{13}$ We halved this figure to take into account the impact of hemodilution in pregnancy. Accordingly, we approximated the postoperative $\mathrm{Hb}$ of women with transfusions according to the following formula: "postoperative $\mathrm{Hb}-0.5 \times$ number of blood cells transfused."

The factors studied included the main risk factors for PPH recognized in the literature and were extracted from the unit's computerized database: maternal age, geographical origin, BMI (body mass index), parity, previous cesarean or other uterine scar, singleton or multiple pregnancy, neonatal weight, prematurity, vascular disease (preeclampsia, hypertension [HTA], proteinuria), duration of labor, and use of oxytocin (for women who had labor). We reviewed the complete records of all women who had had PPH for additional data.

The clinical protocol for PPH, defined as persistent bleeding due to uterine atony, was to use uterotonics agent sulprostone (500- $\mu \mathrm{g}$ IV injection in 1 hour and another $500-\mu \mathrm{g}$ IV injection in 5 hours). French guidelines do not include methylergometrine. The second-line therapies used were intrauterine tamponade with a Bakri balloon, vascular ligatures (either uterine or hypogastric), uterine artery embolization, compressive sutures, or hysterectomy.

\section{Statistical Analysis}

Student's $t$-tests or Chi-square tests were used as appropriate (according to the type of variable to be compared between the two groups). Fisher's exact test was used for qualitative variables when the conditions for applying the Chi-square test were 
not met. The analysis was performed for the overall population and then stratified for women who had a cesarean before labor and those with one during labor. A logistic regression analysis was performed to adjust for confounding factors. Factors included in the logistic regression for the overall population and the population of women with a prelabor cesarean to study the risk of PPH were maternal age ( $>$ or $\leq 35$ years), BMI ( $>$ or $\leq 30$ ), country of birth, previous cesarean or uterine surgery, macrosomia, multiple pregnancy, preterm birth $<37$ WG, multiparity, preeclampsia/gestational hypertension. Factors included in the logistic regression for the subgroup of women who had a cesarean during labor also included labor duration and the use of oxytocin in the model. A $p$-value $<0.05$ was considered to be significant.

The statistical analysis was performed with Stata 13.0 software, TX.

\section{Results}

During the study period, 1,867 women had cesarean deliveries. After the exclusion of 71 , the study included 1,796 women: 987 in period A and 809 in period B (-Fig. 1).

The populations of the two study periods were comparable for socioeconomic and obstetric characteristics, except that women in period A were 2 years older at this cesarean delivery and had a higher prevalence of previous cesareans and other uterine scars ( 43 vs. $38 \%, p=0.04$ ) (-Table 1 ).

Overall, $52 \%$ of the cesareans were performed before labor. Among them, $15 \%$ of the women had a PPH and $0.8 \%$ a severe $\mathrm{PPH}$. Blood cell transfusion was required in $0.7 \%$ of the cases.

- Table 2 reports the maternal and neonatal outcomes overall and according to timing of the cesarean. The PPH rate was lower in period B than in period A (13 vs. $17 \%$,
Table 1 Maternal demographic and obstetrical characteristics

\begin{tabular}{|c|c|c|c|}
\hline & $\begin{array}{l}\text { Period A } \\
N=987 \\
(\%)\end{array}$ & $\begin{array}{l}\text { Period B } \\
N=809 \\
(\%)\end{array}$ & p-Value \\
\hline Age (mean $\pm S D)$ & $34 \pm 5.5$ & $32 \pm 5.5$ & $<0.01$ \\
\hline $\mathrm{BMI}>30$ & $244(25 \%)$ & $219(27 \%)$ & 0.25 \\
\hline \multicolumn{4}{|l|}{ Country of birth } \\
\hline France & $284(29 \%)$ & $210(26 \%)$ & \multirow[t]{4}{*}{0.50} \\
\hline North Africa & $350(35 \%)$ & $308(38 \%)$ & \\
\hline Sub-Saharan Africa & $229(23 \%)$ & $182(22 \%)$ & \\
\hline Others & $118(12 \%)$ & $102(13 \%)$ & \\
\hline $\begin{array}{l}\text { Previous cesarean } \\
\text { or uterine surgery }\end{array}$ & $422(43 \%)$ & $308(38 \%)$ & 0.04 \\
\hline Multiple pregnancy & $71(7 \%)$ & $58(7 \%)$ & 0.95 \\
\hline Nulliparous & 736 (75\%) & $596(74 \%)$ & 0.66 \\
\hline $\begin{array}{l}\text { Preeclampsia or } \\
\text { gestational } \\
\text { hypertension }\end{array}$ & $101(10 \%)$ & $80(10 \%)$ & 0.81 \\
\hline $\begin{array}{l}\text { Preterm birth } \\
<37 \mathrm{w} \text { of } \\
\text { gestation }\end{array}$ & $211(21 \%)$ & $158(20 \%)$ & 0.33 \\
\hline Birth weight $(g) \pm S D$ & $3,018 \pm 866$ & $3,033 \pm 928$ & 0.72 \\
\hline Birth weight $>4,000 \mathrm{~g}$ & $80(8.1 \%)$ & $79(9.8 \%)$ & 0.22 \\
\hline Cesarean before labor & 481 (49\%) & $454(56 \%)$ & \\
\hline Cesarean during labor & $506(51 \%)$ & $355(44 \%)$ & \\
\hline Oxytocin during labor ${ }^{\mathrm{a}}$ & $\begin{array}{l}347 / 506 \\
(69 \%)\end{array}$ & $\begin{array}{l}247 / 355 \\
(70 \%)\end{array}$ & 0.75 \\
\hline $\begin{array}{l}\text { Length of labor } \\
(\mathrm{h})^{\mathrm{a}} \pm \mathrm{SD}\end{array}$ & $7.3 \pm 4.3$ & $8.3 \pm 4.6$ & 0.001 \\
\hline
\end{tabular}

Abbreviations: BMI, body mass index; SD, standard deviation. ${ }^{a} 506$ patients went into labor during period $A$ and 355 during period $B$.

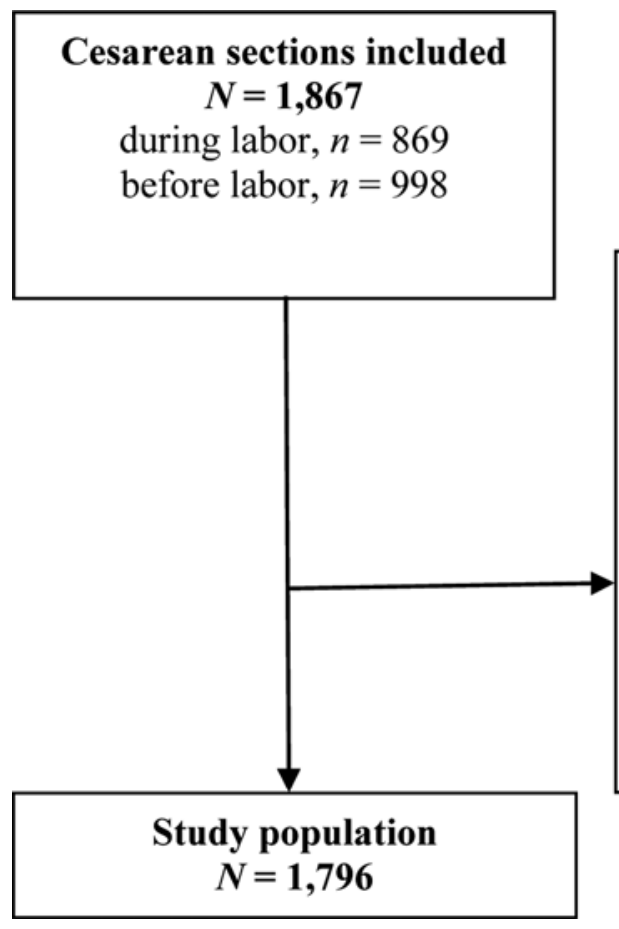

Exclusions: $N=71$

Placenta praevia $(n=39)$

Abruption $(n=25)$

Myoma praevia $(n=6)$

Thrombopenia $(n=5)$

Uterine artery lesions $(n=2)$

Coagulation disorders $(n=0)$

Uterine rupture $(n=0)$

Transfusion for preexisting anemia $(n=0)$

Fig. 1 Flowchart. 
Table 2 Maternal and neonatal outcomes according to timing of cesarean

\begin{tabular}{|l|l|l|l|l|}
\hline & Period A & Period B & OR & aOR (95\% Cl) \\
\hline Overall population & $n=987(\%)$ & $n=809(\%)$ & & \\
\hline Postpartum hemorrhage & $163(17)$ & $105(13)$ & $0.75(0.58-0.98)$ & $0.81(0.61-1.06)^{\mathrm{a}}$ \\
\hline Severe postpartum hemorrhage & $11(1)$ & $4(0.5)$ & $0.44(0.14-1.40)$ & $0.47(0.14-1.53)^{\mathrm{a}}$ \\
\hline Use of additional uterotonics (sulprostone) & $26(3)$ & $12(1)$ & $0.56(0.28-1.11)$ & $0.58(0.28-1.17)^{\mathrm{a}}$ \\
\hline Red blood cell transfusion & $7(0.7)$ & $6(0.7)$ & $1.04(0.35-3.13)$ & $0.98(0.31-3.06)^{\mathrm{a}}$ \\
\hline Conservative surgery & $6(0.6)$ & $1(0.1)$ & $0.21(0.02-1.72)$ & - \\
\hline Intrauterine tamponade & $5(0.5)$ & $1(0.1)$ & $0.25(0.03-2.12)$ & - \\
\hline Embolization/Hysterectomy & 0 & 0 & - & - \\
\hline Women who had a cesarean during labor & $n=506(\%)$ & $n=355(\%)$ & & \\
\hline Postpartum hemorrhage & $107(21)$ & $64(18)$ & $0.82(0.58-1.15)$ & $0.77(0.54-1.11)^{\mathrm{b}}$ \\
\hline Severe postpartum hemorrhage & $6(1)$ & $3(0.8)$ & $0.71(0.18-2.86)$ & $0.87(0.18-4.12)^{\mathrm{b}}$ \\
\hline Use of additional uterotonics (sulprostone) & $15(3)$ & $8(2)$ & $0.75(0.32-1.80)$ & $0.79(0.31-2.0)^{\mathrm{b}}$ \\
\hline Red blood cell transfusion & $4(0.8)$ & $2(0.6)$ & $0.71(0.13-3.90)$ & - \\
\hline Conservative surgery & $3(0.6)$ & $1(0.3)$ & $0.47(0.05-4.57)$ & - \\
\hline Intrauterine tamponade & $3(0.6)$ & $1(0.3)$ & $0.47(0.05-4.57)$ & - \\
\hline Embolization/Hysterectomy & 0 & 0 & - & - \\
\hline Women who had a cesarean before labor & $n=481(\%)$ & $n=454(\%)$ & & \\
\hline Postpartum hemorrhage & $56(12)$ & $41(9)$ & $0.75(0.49-1.15)$ & $0.79(0.51-1.23)^{\mathrm{a}}$ \\
\hline Severe postpartum hemorrhage & $5(1)$ & $1(0.2)$ & $0.21(0.02-2.81)$ & $0.20(0.02-1.81)^{\mathrm{a}}$ \\
\hline Use of additional uterotonics (sulprostone) & $11(2)$ & $4(0.9)$ & $0.38(0.12-1.20)$ & $0.35(0.15-1.15)^{\mathrm{a}}$ \\
\hline Red blood cell transfusion & $3(0.6)$ & $4(0.9)$ & $1.42(0.32-6.36)$ & - \\
\hline Conservative surgery & $3(0.6)$ & 0 & - & - \\
\hline Intrauterine tamponade & $2(0.4)$ & 0 & - & - \\
\hline Embolization/Hysterectomy & 0 & 0 & - & - \\
\hline
\end{tabular}

Abbreviations: aOR, adjusted odds ratio; $\mathrm{BMI}$, body mass index; $\mathrm{Cl}$, confidence interval; OR, odds ratio.

${ }^{a}$ Model 1: Factors included were maternal age ( $>$ or $\leq 35 \mathrm{y}$ ), BMI ( $>$ or $\leq 30$ ), country of birth, previous cesarean section or uterine surgery, macrosomia, multiple pregnancy, preterm birth $<37$ wk of gestation, multiparity, preeclampsia/gestational hypertension.

${ }^{b}$ Model 2: Factors included were maternal age ( $>$ or $\leq 35$ y), BMI ( $>$ or $\leq 30$ ), country of birth, previous cesarean or uterine surgery, macrosomia, multiple pregnancy, preterm birth $<37 \mathrm{wk}$ of gestation, multiparity, preeclampsia/gestational hypertension, as well as labor duration and the use of oxytocin.

respectively, odds ratio $0.75,95 \%$ confidence interval $[\mathrm{CI}]$ $0.58-0.98)$. Nonetheless, the difference was no longer significant in the multivariate analysis (adjusted odds ratio: 0.81 , $95 \% \mathrm{Cl} 0.61-1.06)$. Results were similar in the two subgroups -women with a cesarean before labor and those with cesarean during labor. Similar trends were shown for the rates of use of additional uterotonics, red blood cell transfusion, conservative surgery, and uterine tamponade. There was no arterial embolization or hysterectomy in any group.

\section{Discussion}

This study shows that a single injection of carbetocin is not superior to a standard protocol of an injection of oxytocin followed by 20 units in 24 hours for preventing PPH after a cesarean before or during labor.

The main strength of our study is the large number of women included. This is, by far, the largest study to date comparing oxytocin and carbetocin. ${ }^{14-24}$ They were powered to detect a difference of 40 to $50 \%$ reduction of PPH (defined by $500 \mathrm{~mL}$ ) in a population in which 17 to $18 \%$ of the women were treated by oxytocin. It seems unlikely to us that carbetocin could provide so much greater a benefit than oxytocin. Our study was designed to detect a $25 \%$ difference for the outcome, which seems much more realistic.

Another important strength of our study was the use of an objective method to quantify PPH. The quantification of blood loss is difficult, especially during a cesarean when blood loss is necessarily mixed with amniotic fluid. Moreover, during surgery, blood is also collected through compresses making the blood loss quantification even more difficult. Therefore, blood loss is frequently underestimated. ${ }^{25,26}$ The difference between pre- and postoperative $\mathrm{Hb}$ concentration is the most objective approach for accurately evaluating blood loss after cesarean deliveries, and this method has frequently been used to evaluate blood loss after PPH..$^{27,28}$ In previous studies, the primary outcome used has often been subjective, such as uterine atony or the need for other uterotonics. ${ }^{15,17-20,22,23}$ 
In nonblinded trials, this might well have led to observation bias.

Another strength of the study was that all data were collected prospectively. Moreover, we had data on the management of labor in each case. We were thus able to adjust our results for intrapartum cesareans for labor duration and early use of oxytocin, both major risk factors for $\mathrm{PPH}{ }^{29,30}$

The main weakness of our study is that it was not a randomized double-blinded study, which would provide the highest level of proof for comparing the efficacy of carbetocin and oxytocin in preventing PPH. Another is that other factors might have changed between the two consecutive periods, in particular, changes in some members of the medical team in this university center. However, written medical protocols and a daily meeting reviewing all women who gave birth during the past 24 hours guarantee the continuity of medical care. There was no other change in protocols/type and dose of drugs for PPH management over the period of the study. Another weakness is the absence of a strict protocol for the timing of blood samples to calculate the difference between pre- and post-cesarean $\mathrm{Hb}$. It is unlikely, however, that this could influence the results since nearly all maternal blood samples were taken the day after the cesarean.

This study is consistent with the most recent Cochrane analysis. ${ }^{9}$ Similarly, other studies also using the change in $\mathrm{Hb}$ as an outcome found no significant difference between carbetocin and oxytocin. ${ }^{18,22}$ One trial with protocols similar to ours ( 1 bolus of oxytocin of 5 IU followed by a maintenance dose of $20 \mathrm{IU}$ for 8 hours vs. $100 \mu \mathrm{g}$ carbetocin) and including 635 women also found similar PPH rates in the two arms. ${ }^{20}$

Some studies using the need for additional uterotonics as the main outcome have reported carbetocin to be superior. ${ }^{18,20,31}$ This outcome, however, is highly subjective and not a direct maternal health end point. The use of other uterotonics varies quite substantially between obstetrics professionals, because it relies on the subjective evaluation of bleeding and the expected risk of failure of the prophylactic injection used. Similarly, some studies have chosen uterine atony or the need for uterine massage as end points, but they have the same drawbacks. ${ }^{19,20}$

Although not superior to oxytocin in preventing $\mathrm{PPH}$, carbetocin allows the early removal of IV lines, which is a component of current protocols for enhanced recovery after cesarean deliveries. ${ }^{32}$ Some cost-benefit analyses have shown that reductions in retreatment, staffing requirements, transfusions, and potential medication errors mitigate carbetocin's higher initial cost. ${ }^{33,34}$ Therefore, from a pharmacoeconomic perspective, carbetocin may be cost-effective as prophylaxis against PPH in cesarean deliveries.

In conclusion, even in this large sample, carbetocin is not superior to oxytocin in preventing $\mathrm{PPH}$. It does provide the advantage of requiring a single injection.

\section{Conflict of Interest}

None.

\section{References}

1 Say L, Chou D, Gemmill A, et al. Global causes of maternal death: a WHO systematic analysis. Lancet Glob Health 2014;2(06): e323-e333

2 Saucedo M, Deneux-Tharaux C, Bouvier-Colle MH; French National Experts Committee on Maternal Mortality. Ten years of confidential inquiries into maternal deaths in France, 1998-2007. Obstet Gynecol 2013;122(04):752-760

3 Kayem G, Deneux-Tharaux C. Invasive therapies for primary postpartum haemorrhage as missed opportunities for medical prevention. Curr Opin Obstet Gynecol 2017;29(02):66-70

4 Dahlke JD, Mendez-Figueroa H, Maggio L, et al. Prevention and management of postpartum hemorrhage: a comparison of 4 national guidelines. Am J Obstet Gynecol 2015;213(01):76. e1-76.e10

5 Westhoff G, Cotter AM, Tolosa JE. Prophylactic oxytocin for the third stage of labour to prevent postpartum haemorrhage. Cochrane Database Syst Rev 2013;10(10):CD001808

6 Sheldon WR, Blum J, Vogel JP, Souza JP, Gülmezoglu AM, Winikoff B; WHO Multicountry Survey on Maternal and Newborn Health Research Network. Postpartum haemorrhage management, risks, and maternal outcomes: findings from the World Health Organization Multicountry Survey on Maternal and Newborn Health. BJOG 2014;121(Suppl 1):5-13

7 WHO WHO Recommendations for the Prevention and Treatment of Postpartum Haemorrhage. 2012Geneva: WHO; 2012. Available at: http://apps.who.int/iris/bitstream/10665/75411/1/97892415 48502_eng.pdf. Accessed March 24, 2020

8 Kayem G, Dupont C, Bouvier-Colle MH, Rudigoz RC, DeneuxTharaux C. Invasive therapies for primary postpartum haemorrhage: a population-based study in France. BJOG 2016;123(04): 598-605

9 Gallos ID, Papadopoulou A, Man R, et al. Uterotonic agents for preventing postpartum haemorrhage: a network meta-analysis. Cochrane Database Syst Rev 2018;12:CD011689

10 Gallos I, Williams H, Price M, et al. Uterotonic drugs to prevent postpartum haemorrhage: a network meta-analysis. Health Technol Assess 2019;23(09):1-356

11 Gallos ID, Coomarasamy A. Carbetocin: worth the extra expense? Best Pract Res Clin Obstet Gynaecol 2019;61:55-65

12 Zhang WH, Deneux-Tharaux C, Brocklehurst P, Juszczak E, Joslin M, Alexander S; EUPHRATES Group. Effect of a collector bag for measurement of postpartum blood loss after vaginal delivery: cluster randomised trial in 13 European countries. BMJ 2010;340:c293

13 Silberstein L, Anastasi J. Principles of red blood cell transfusion. In: Hoffman K, ed. Hematology: Basic Principles and Practice. 6th ed. Orlando, FL: Churchill Livingstone; 2012

14 Boucher M, Horbay GL, Griffin P, et al. Double-blind, randomized comparison of the effect of carbetocin and oxytocin on intraoperative blood loss and uterine tone of patients undergoing cesarean section. J Perinatol 1998;18(03):202-207

15 Elgafor el Sharkwy IA. Carbetocin versus sublingual misoprostol plus oxytocin infusion for prevention of postpartum hemorrhage at cesarean section in patients with risk factors: a randomized, open trail study. Arch Gynecol Obstet 2013;288(06):1231-1236

16 Moertl MG, Friedrich S, Kraschl J, Wadsack C, Lang U, Schlembach D. Haemodynamic effects of carbetocin and oxytocin given as intravenous bolus on women undergoing caesarean delivery: a randomised trial. BJOG 2011;118(11):1349-1356

17 Reyes OA, Gonzalez GM. Carbetocin versus oxytocin for prevention of postpartum hemorrhage in patients with severe preeclampsia: a double-blind randomized controlled trial. J Obstet Gynaecol Can 2011;33(11):1099-1104

18 Attilakos G, Psaroudakis D, Ash J, et al. Carbetocin versus oxytocin for the prevention of postpartum haemorrhage following caesarean section: the results of a double-blind randomised trial. BJOG 2010;117(08):929-936 
19 Borruto F, Treisser A, Comparetto C. Utilization of carbetocin for prevention of postpartum hemorrhage after cesarean section: a randomized clinical trial. Arch Gynecol Obstet 2009;280(05): 707-712

20 Dansereau J, Joshi AK, Helewa ME, et al. Double-blind comparison of carbetocin versus oxytocin in prevention of uterine atony after cesarean section. Am J Obstet Gynecol 1999;180(3 Pt 1):670-676

21 Askar AA, Ismail MT, El-Ezz AA, Rabie NH. Carbetocin versus syntometrine in the management of third stage of labor following vaginal delivery. Arch Gynecol Obstet 2011;284(06):1359-1365

22 Su LL, Rauff M, Chan YH, et al. Carbetocin versus syntometrine for the third stage of labour following vaginal delivery-a double-blind randomised controlled trial. BJOG 2009;116(11):1461-1466

23 Nirmala K, Zainuddin AA, Ghani NA, Zulkifli S, Jamil MA. Carbetocin versus syntometrine in prevention of post-partum hemorrhage following vaginal delivery. J Obstet Gynaecol Res 2009;35 (01):48-54

24 Leung SW, Ng PS, Wong WY, Cheung TH. A randomised trial of carbetocin versus syntometrine in the management of the third stage of labour. BJOG 2006;113(12):1459-1464

25 Natrella M, Di Naro E, Loverro M, et al. The more you lose the more you miss: accuracy of postpartum blood loss visual estimation. A systematic review of the literature. J Matern Fetal Neonatal Med 2018;31(01):106-115

26 Gluck O, Mizrachi Y, Kovo M, Divon M, Bar J, Weiner E. Major underestimation and overestimation of visual blood loss during cesarean deliveries: can they be predicted? Arch Gynecol Obstet 2017;296(05):907-913

27 Audureau E, Deneux-Tharaux C, Lefèvre P, et al. Practices for prevention, diagnosis and management of postpartum haemor- rhage: impact of a regional multifaceted intervention. BJOG 2009; 116(10):1325-1333

28 Deneux-Tharaux C, Dupont C, Colin C, et al. Multifaceted intervention to decrease the rate of severe postpartum haemorrhage: the PITHAGORE6 cluster-randomised controlled trial. BJOG 2010; 117(10):1278-1287

29 Belghiti J, Coulm B, Kayem G, Blondel B, Deneux-Tharaux C. Oxytocin administration during labor. Results from the 2010 French National Perinatal Survey [in French]. J Gynecol Obstet Biol Reprod (Paris) 2013;42(07):662-670

30 Belghiti J, Kayem G, Dupont C, Rudigoz RC, Bouvier-Colle MH, Deneux-Tharaux C. Oxytocin during labour and risk of severe postpartum haemorrhage: a population-based, cohort-nested case-control study. BMJ Open 2011;1(02):e000514

31 El Behery MM, El Sayed GA, El Hameed AA, Soliman BS, Abdelsalam WA, Bahaa A. Carbetocin versus oxytocin for prevention of postpartum hemorrhage in obese nulliparous women undergoing emergency cesarean delivery. J Matern Fetal Neonatal Med 2016; 29(08):1257-1260

32 Deniau B, Bouhadjari N, Faitot V, et al. Evaluation of a continuous improvement programme of enhanced recovery after caesarean delivery under neuraxial anaesthesia. Anaesth Crit Care Pain Med 2016;35(06):395-399

33 Henríquez-Trujillo AR, Lucio-Romero RA, Bermúdez-Gallegos K. Analysis of the cost-effectiveness of carbetocin for the prevention of hemorrhage following cesarean delivery in Ecuador. J Comp Eff Res 2017;6(06):529-536

34 Voon HY, Shafie AA, Bujang MA, Suharjono HN. Cost effectiveness analysis of carbetocin during cesarean section in a high volume maternity unit. J Obstet Gynaecol Res 2018;44(01):109-116 